\title{
The Patron Game with Heterogeneous Endowments: A Case against Inequality Aversion
}

\author{
Antonio Filippin ${ }^{\mathrm{a}}$ \\ Manuela Raimondi ${ }^{\mathrm{b}}$
}

\begin{abstract}
In this paper we provide a direct test of the inequality aversion hypothesis based on aggregate outcomes using the Patron Game, a version of a Public Good Game that mandates that only one member of a group contribute to the public good.

We find evidence that inequality aversion does not play any role, as the average contribution does not increase when the distribution of endowments is manipulated to generate a situation of favorable inequality for the patron, compared to the case in which there is no inequality ex ante.
\end{abstract}

Keywords: Public Good, Inequality Aversion, Altruism

JEL Codes: C90; D63; H41

\footnotetext{
${ }^{\text {a }}$ Corresponding author, University of Milan, Department of Economics, Via Conservatorio 7, 20122 Milano (Italy). Phone: +39 02503 21536. Fax: +39 02503 21505. Email: antonio.filippin@ unimi.it.

${ }^{\mathrm{b}}$ University of Parma, Department of Economics, Via Kennedy 6, 43125 Parma (Italy). Phone: +39 0521 032413. Fax: +39 0521 032402. Email: manuela.raimondi@unimi.it.
} 


\section{Introduction}

Several experimental studies show that individuals tend to resist inequitable outcomes and are willing to give up (part of) their monetary payoffs to decrease the degree of inequality within a group. Inequality Aversion (IA) has gained considerable attention in the literature as one of the most prominent models of other-regarding preferences aimed at explaining these departures from purely selfish behavior. This concept has been formalized by several models, the most representative of which are Fehr and Schmidt (1999) and Bolton and Ockenfels (2000). Inequity aversion has been invoked to explain the evidence observed in many standard experimental settings in which inequality stems from the heterogeneity between the endowment of the "rich" players (dictator, proposer, trustor) and that of the "poor" counterpart (recipient, respondent, trustee). For instance, Fehr and Schmidt (1999) claim that their model is able to rationalize the results of many ultimatum games (Kahneman, et al., 1986b; Guth et al. 1982; Cameron, 1995; Hoffman, et al., 1996; Slonim and Roth, 1997), dictator games (Forsythe, et al., 1994; Andreoni and Miller, 2002), gift exchange games (Fehr et al., 1993; Berg et al., 1995; Fehr, Gaechter and Kirchsteiger, 1997), and bargaining and market games (Roth et al., 1991; Guth et al., 1997). Fehr and Schmidt (1999) also apply the IA model to some standard Public Good Games such as those by Isaac and Walker (1988), Andreoni (1988, 1995a, 1995b) Croson (1995, 1996), Keser and Van Winden (1996), Ockenfels and Weimann (1999), Burlando and Hey (1997). ${ }^{1}$

Public Good experiments have also been used to test IA by using a heterogeneous distribution of endowments. The evidence obtained is mixed: while some studies show that heterogeneity increases voluntary contributions (Chan et al., 1996), many others deliver opposite findings (Anderson et al. 2003; Buckley and Croson 2006; Cardenas, 2002a,b; Ledyard, 1995; Isaac and Walker, 1988) or null results (Varughese and Ostrom, 2001).

A natural question is therefore whether it is possible (and how) to reconcile this large body of mixed evidence. From a theoretical point of view, the mixed evidence could stem from the very different characteristics of the aforementioned games. For instance, while the Dictator Game and Ultimatum Game are characterized by different sets of choice (typically, the rich have more power to shape the final outcomes), the actions are instead symmetric in the Public Good Game. The degree of strategic complexity also differs across games, and so do efficiency concerns, which are particularly relevant in Public Good and Trust Games.

From an empirical point of view, the experimental evidence usually emphasizes results that are consistent with the IA hypothesis. However, these games do not constitute a clean test of the IA model because other competing causes can rationalize the results. Shaked (2006) criticizes the IA models because they lack a well-defined explanatory power. Relying on heterogeneous preferences at the individual level, the models can account for virtually every aggregate outcome. There are instead few attempts to directly test IA models. Engelmann and Strobel (2004) use a distributional game in which intentions play no role because the distribution of the payoffs is decided by a disinterested third party. The results do not find that IA plays a significant role as compared to that of other explanatory factors such as efficiency concerns. $^{2}$ A similar trade-off between increasing aggregate payoffs and reducing inequality

\footnotetext{
${ }^{1}$ Inequality aversion has also been proposed as a determinant of behavior in Gift Exchange and Market Games in the lab, as well as of the changes in performance that may follow the introduction of heterogeneous incentives in the same workgroup (Akerlof and Yellen, 1990; Bewley, 1999; Winter 2004, Goerg et al., 2010, Abeler et al., 2010).

${ }^{2}$ Bolton and Ockenfels (2006) emphasize that in Engelmann and Strobel (2004) the cost to achieve efficiency is lower than the cost to achieve equality, providing evidence in favor of inequality aversion when the cost for efficiency rises. Fehr, Naef and Schmidt (2006) show that efficiency concerns are more important when the
} 
has also been emphasized by Charness and Rabin (2002), and Fisman et al. (2005). Yamagishi et al. (2009) find that IA cannot account for the results in a modified Ultimatum Game in which the respondent by rejecting the offer does not affect the payoff of the proposer.

In our opinion a proper test of IA should feature an exogenous manipulation of the degree of inequality ceteris paribus, thereby neutralizing possible confounding factors. Such a design would also make the predictions of the models falsifiable at the aggregate level, i.e. without stretching the model to make point predictions and without requiring a specific functional form of the IA hypothesis.

To our knowledge, the only test of the IA models along these lines is provided in Korenok, Millner and Razzolini (2011), who manipulate the degree of heterogeneity of the endowments in a Dictator Game. The authors find that the majority of dictators exhibit behavior that is consistent with inequality averse preferences, distributing more money when the recipients are poorer $(75 \%$ of dictators distribute at least $30 \%$ of the endowment) than when endowments are equal (only $25 \%$ of dictators distribute a positive but lower share, about $12 \%$ of the endowment). These results definitely support the IA hypothesis, but they are possibly affected by a within-subject design that might induce a correlation between the degree of inequality and the choices, as well as by role uncertainty which might trigger indirect reciprocity.

In this paper, we propose a simple and direct test of IA models using the Patron Game (Filippin and Raimondi, 2015), an environment that is suitable to manipulate the degree of inequality and in which strategic considerations play no role. The value added of our contribution is twofold. First, we chose a pure between-subject design to avoid that being exposed to different levels of inequality may trigger some demand effects. Second, the use of the Patron Game with heterogeneous endowments allows IA to be tested in a framework where the goal of reducing inequality is aligned and therefore does not compete with efficiency concerns.

Our results show that the presence of unequal endowments does not significantly increase the average contributions in the Patron Game. Moreover, in the treatment without heterogeneity, the results would even point toward subjects being on average inequality seeking if interpreted within IA models.

The structure of the paper is as follows. In Section 2, we summarize the theoretical framework of IA. In Section 3, we present the Patron Game and the treatments of our experimental design. Section 4 illustrates the data analysis and the interpretation of the results. Finally, Section 5 concludes.

\section{Theoretical framework}

Among the many models that rationalize departures from purely selfish behavior by means of other-regarding preferences, Fehr and Schmidt (1999) and Bolton and Ockenfels (2000) formalize the idea of inequality aversion. Both models are outcome-based, i.e. they do not

proposers are economics students but that inequality aversion tends to drive the behavior of other types of proposers. 
investigate the ultimate cause behind the willingness to reduce inequality. As such, the models can encompass the effect of guilt aversion, demand effects, etc.

Fehr and Schmidt (1999) consider a set of $n$ players indexed by $i \in(1, \ldots, n)$ and a vector of monetary payoffs $x=x_{1}, \ldots, x_{n}$ evaluated according to the following utility function:

$$
\text { (1) } U_{i}(x)=x_{i}-\alpha_{i} \frac{1}{n-1} \sum_{j \neq i} \max \left\{x_{j}-x_{i}, 0\right\}-\beta_{i} \frac{1}{n-1} \sum_{j \neq i} \max \left\{x_{i}-x_{j}, 0\right\} . \quad i \neq j
$$

The second term is the utility loss derived from disadvantageous inequality, and the third term is the loss derived from advantageous inequality. The parameter $0<\beta_{i} \leq 1$ is a measure of the agent's willingness to trade off his payoff with advantageous inequality. In the limit case of $\beta_{i}=1$, an increase of the individual payoff $x_{i}$ brings no additional utility if it also translates into an equivalent increase in inequality. The common assumption that $\beta_{i}<\alpha_{i}$ captures the fact that the agent suffers more from disadvantageous inequality. This specification implies a self-centered interpretation of IA, since the agent is not averse to differences among the opponents. In contrast, subjects care about the fairness of their own payoff relative to the payoffs of the opponents.

Another feature of (1) is that it is linear in inequality as well in $x$, and therefore the marginal rate of substitution between income and inequality is constant. Although this assumption could be relaxed, the model appears to explain many experimental results in its simplified version, too. In any case, the design of our experiment, explained in Section 3, is meant to test the concept of IA without assuming any specific functional form.

In Bolton and Ockenfels (2000), the utility function combines self-interest motivations with a concern for one's relative standing inside the group. The utility function is maximized when one's own share is equal to the average. Both models rationalize that the subjects with a higher income should be willing to transfer part of it to poorer counterparts. The main difference between the two models is that Fehr and Schmidt compare one's payoffs with that of any other opponent, implying that subjects prefer that everybody receives the same payoff. In contrast, in Bolton and Ockenfels (2000) utility is maximized as long as the player receives the average payoff, regardless of whether there are rich and poor among the opponents. ${ }^{3}$ However, the two models are indistinguishable in our treatments, as there is no inequality among the opponents.

\section{Design}

The Patron Game can be summarized as a standard Public Good Game in which only $K \leq N$ members of the group decide their contribution level, while the other $N-K$ subjects are characterized by a passive role and do not contribute.

The patrons can allocate their endowment $e_{i}$ between an individual account with a 1:1 return (therefore equivalent to saving because it enters directly the subject's earnings) and a collective fund whose size $F$ is characterized by the usual production function:

$$
F=1.5 \sum_{i=1}^{K} c_{i}
$$

\footnotetext{
${ }^{3}$ For instance, the Fehr and Schmidt model predicts that the voter with the average income would support a tax levied on the upper class to subsidize the poor, while the Bolton and Ockenfels model does not.
} 
where 1.5 is the efficiency multiplier and $c_{i}$ are the individual contributions.

The contribution of the passive members is instead $c_{i}=0$ by construction, and they will simply receive their share of the public fund on top of their initial endowment.

The Patron Game allows us to manipulate the degree of inequality by means of the initial endowments. We concentrate on a Patron Game in which strategic interaction considerations are entirely removed, i.e., when $K=1$. Only one player (the patron) can decide if and how much to contribute to the public good without uncertainty about the behavior of other players who are known to be characterized by a passive role. ${ }^{4}$ We keep the roles (active and inactive) constant through the 10 rounds following a partner design, which means that in every group of four subjects three do not make any choice during the experiment. ${ }^{5} \mathrm{We}$ also decide to avoid role uncertainty, i.e. we do not elicit the choice of each subject as patron before assigning their actual role although it would have allowed us to increase the number of observations. The reason is that role uncertainty could have an effect similar to that of the veil of ignorance, which induces the subjects to consider the final outcomes from all the possible points of view. In other words, knowing that one could end up among the poor subjects is likely to render the payoff of the inactive players more salient, thereby increasing the contributions and overestimating the effect of IA (see for instance Iriberri and Rey-Biel, 2011).

\subsection{Treatment 1: Patron Game with heterogeneous endowments (K1_Unequal)}

Our baseline treatment is characterized by $\mathrm{K}=1$ and heterogeneous endowments. The patron is endowed with 150 tokens in each round, while the other three inactive players are endowed with 50 tokens. $^{6}$ The contribution of the patron is then multiplied by an efficiency factor equal to 1.5 and equally distributed among the 4 members. This framework implies a marginal percapita return equal to 0.375 . Hence, the dominant strategy of the patron given a selfish behavior would be to contribute nothing. However, IA can motivate the wealthiest subject to contribute a positive amount with the goal of reducing ex ante inequality (a contribution of 100 would equalize ex post earnings). Note that in this treatment a positive contribution does at the same time reduce the difference between payoffs and increase the aggregate earnings. In principle, this constitutes a hospitable environment for IA, which has been instead found to be reduced by the presence of efficiency concerns. ${ }^{7}$

It is worth stressing that in not all the patrons are expected to contribute because of IA considerations. For instance, calibrating the Fehr and Schmidt utility function (1) in our experiment it turns out that only the subjects characterized by $\beta>.625$ should sacrifice part of their initial endowment. Relying upon distributions of the $\beta$ parameter such as those proposed

\footnotetext{
${ }^{4}$ The Patron Game also allows to manipulate the degree of strategic interaction between the limits given by $K=$ 1 and $K=N$, which corresponds to the classic PG game. The original design of our experiment also included two additional treatments manipulating the number of active players ( 2 and 4 , respectively) with the goal of analyzing the additional role played by strategic interaction in a framework characterized by heterogeneous endowments. Two anonymous referees raised careful concerns about the efficacy of such treatments, convincing us to drop them from the paper. Details and results are available upon request.

${ }^{5}$ The choice of a partner design is mainly driven by the concern of maximizing the number of independent observations.

${ }^{6} 100$ tokens $=1$ Euro

${ }^{7}$ This treatment is not characterized by a Pareto superior outcome because any positive contribution makes the patron worse off by construction as compared to the initial situation. Moreover, there is no scope to contribute because of reciprocity or conditional cooperation aimed at increasing individual payoffs since $\mathrm{K}=1$.
} 
by Fehr and Schmidt (1999) or estimated by Blanco, Engelmann \& Normann (2011) one could expect about $40 \%$ of the patrons to contribute in our K1_Unequal treatment.

\subsection{Treatment 2: The Patron Game with equal endowments (K1_Equal) ${ }^{8}$}

This treatment is identical to the previous one, except that there is no inequality ex ante, because the endowments are equal to 100 for every subject. ${ }^{9}$ Hence, the possible role of IA has been neutralized, while any other reason to contribute is common to Treatment 1 . Note that by contributing any positive amount, the patron generates ex post unfavorable inequality because his payoffs would, by construction, be lower than those of the inactive players. Hence, as long as $\alpha>0$ in (1) as commonly assumed, the IA model predicts that contributions should be equal to zero. However, there are other factors that could possibly drive contributions in the positive domain (efficiency concerns, the warm glow of giving, demand effects, and confusion). Therefore, observing positive contributions cannot be interpreted per $s e$ as evidence that IA plays no role but rather, more conservatively, that its magnitude is of second order importance as compared to that of alternative explanations.

While a selfish behavior induces the same choice as in Treatment 1, IA considerations imply different predictions: in the version with heterogeneous endowments the patrons should contribute to reduce inequality, while under the condition of equal endowments, all patrons should contribute zero.

Note that we do not intend to force the model in (1) to any point prediction because that would constitute an excessively stringent requirement. We simply exploit the fact that the Fehr and Schmidt model predicts positive contributions only in Treatment 1 under reasonable assumptions about the underlying distribution of parameters in the subject pool $(\alpha>0$ and $\beta$ not too low).

Table 1. List of treatments. $m=1.5, \mathrm{~N}=4$ in all treatments.

\begin{tabular}{lccccccc}
\hline & Treatment & $\begin{array}{c}\text { N. of } \\
\text { independent } \\
\text { observations }\end{array}$ & $\boldsymbol{K}$ & $\boldsymbol{e}_{\boldsymbol{p}}$ & $\boldsymbol{e}_{-p}$ & $\begin{array}{c}\text { Choice } \\
\text { set }\end{array}$ & Het. \\
\hline $\mathbf{1}$ & K1_Unequal & 20 & 1 & 150 & 50 & {$[0,150]$} & YES \\
\hline $\mathbf{2}$ & K1_Equal & 20 & 1 & 100 & 100 & {$[0,100]$} & NO \\
\hline
\end{tabular}

In both treatments, which are summarized in Table 1, other factors such as efficiency concerns, demand effects, altruism and confusion may be at work driving positive contributions. ${ }^{10}$ However, their effect should not differ across treatments and therefore differences in the results across treatments could only be ascribed to the heterogeneity of the endowments.

\footnotetext{
${ }^{8}$ The data of this treatment have also been used in Filippin and Raimondi (2015).

${ }^{9}$ The choice of such endowments is a compromise aimed at avoiding extreme differences both in the endowment of the patron and in the total amount of money distributed across treatments.

${ }^{10}$ Filippin and Raimondi (2015) show that demand effects and, to a lower extent, the warm glow of giving, are relatively more important explanatory of contributions in the Patron Game, while efficiency concerns and confusion play a minor role.
} 
Testable implication: if IA plays a role, the average relative contributions in Treatment 1 should be significantly higher than those in Treatment $2 .{ }^{11}$

Note that we are not making assumptions about the specific transmission mechanism going from heterogeneous endowments to the patron's choice. Being relatively richer could, for instance, trigger stronger demand effects or increase guilt aversion, something that would have observationally equivalent effects in terms of disutility of unequal payoffs. This structure strictly parallels the theoretical formulation of the IA model, which is outcome based and does not specify the ultimate cause behind the disutility of unequal outcomes.

\subsection{Procedures}

Our experimental sessions were conducted between January 2011 and May 2012 at the Experimental Laboratory of the University of Parma, recruiting 160 voluntary subjects among undergraduate students from different degree programs. Subjects had no previous exposure either to laboratory experiments about social preferences or to courses in Economics and Mathematics.

The participants were randomly assigned a desk and received written instructions (see Appendix) that were also read aloud. In both treatments, the Patron Game was played among groups of 4 subjects who were randomly and anonymously matched at the beginning of the experiment, which it then followed a partner design throughout the 10 rounds. The main characteristics of each treatment are summarized in Table 2.

Table 2. List of Treatments, 10 rounds, $N=4$ in all treatments.

\begin{tabular}{ccccccccccc}
\hline & \multirow{2}{*}{ Treatment } & \multicolumn{2}{c}{$\begin{array}{c}\text { N. of } \\
\text { participants }\end{array}$} & \multicolumn{2}{c}{ N. of active Indep. } & \multicolumn{3}{c}{ Endowment } & \multicolumn{2}{c}{ Choice set } \\
& & & players & obs. & & rich & poor & rich & poor \\
\hline $\mathbf{1}$ & K1_Unequal & 80 & 20 & 20 & 1 & 150 & 50 & {$[0,150]$} & {$[0]$} \\
$\mathbf{2}$ & K1_Equal & 80 & 20 & 20 & 1 & 100 & 100 & {$[0,100]$} & {$[0]$} \\
\hline
\end{tabular}

After each repetition, the subjects received information about the contribution of the active player in their group. After playing the Patron Game the subjects completed a questionnaire asking for demographic information as well as their comprehension of the task.

The experiment was run using z-Tree (Fischbacher, 2007) and lasted about 35 minutes. The average payoff, including a $2.5 €$ show-up fee, was approximately $12.1 €$. The participants, identified by a number randomly drawn at the beginning of the experiment, received their earnings at the end of their session in a sealed envelope, assuring anonymity with respect both to the experimenter and to the other participants.

\footnotetext{
${ }^{11}$ Note that given that the level of the patron's endowment differs across treatments, we have to refer to relative contributions, i.e., the ratio between the contribution and the endowment.
} 


\section{Results}

In the K1_Unequal the average contribution is $23.7 \%$ of the endowment. This result implies that ex post inequality is lower than ex ante. In fact, the average payoff of the patrons is 2.3 times greater than that of the recipients, while their endowments were 3 times higher. Note further that performing an exercise like that in Fehr and Schmidt (1999), with the minor adjustment of assuming that $40 \%$ of the population is characterized by a $\beta$ slightly higher than .625 instead of .6 would predict a relative contribution of $26.6 \%$. Hence, at first glance the results in K1_Unequal seems to lend support to the IA model. However, in order to test the real effect of payoff inequality we exploit the between subject design and compare whether the average (relative) contribution is higher in Treatment 1 (K1_Unequal) than in Treatment 2 (K1_Equal). Results demonstrate that this is not the case because the average relative contributions are not significantly different and display a very similar point estimate (23.7\% vs. $22 \%$, see Table 3 ).

Table 3. Average percentage contribution for the 10 periods: K1_Unequal vs. K1_Equal

\begin{tabular}{llcccccc}
\hline & \multirow{2}{*}{ Treatment } & \multirow{2}{*}{ Indep. } & \multicolumn{4}{c}{ Average contribution (percentage) } & \multirow{2}{*}{ Mann } \\
& observ. & Mean & St. Dev. & Min & Max & Whitney \\
\hline 1 & K1_Unequal & 20 & 0.237 & 0.215 & 0 & 0.671 & \multirow{2}{*}{0.871} \\
2 & K1_Equal & 20 & 0.220 & 0.179 & 0 & 0.555 & \\
\hline
\end{tabular}

Result: The average relative contribution of the patrons does not significantly increase with the introduction of asymmetric endowments.

Figure 1. Distribution of the average relative contributions: K1_Unequal vs. K1_Equal

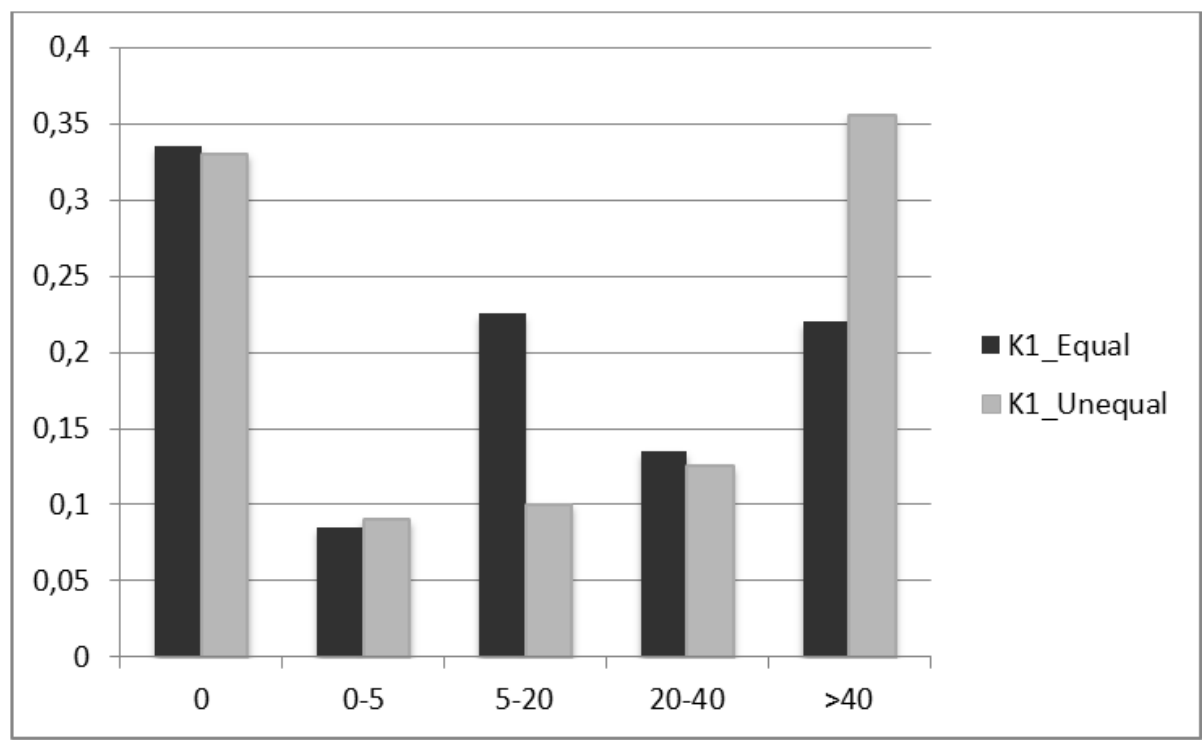


This conclusion is supported by additional evidence. For instance, the two treatments also display a very similar distribution of individual relative contributions $(r)$. As shown in Figure 1 , the fraction of selfish subjects is similar in the two treatments. This result is robust to the inclusion among the selfish players of those who could have made very low but positive contributions by mistake $(0<r \leq 0.05)$. Moreover, only one subject in the K1_Unequal treatment makes an average contribution that is close to the level $(0.66)$ that equalizes final earnings.

Figure 2 shows that the time patterns for the contributions in the two treatments do not differ substantially, too.

Figure 2. Time pattern of average individual contributions

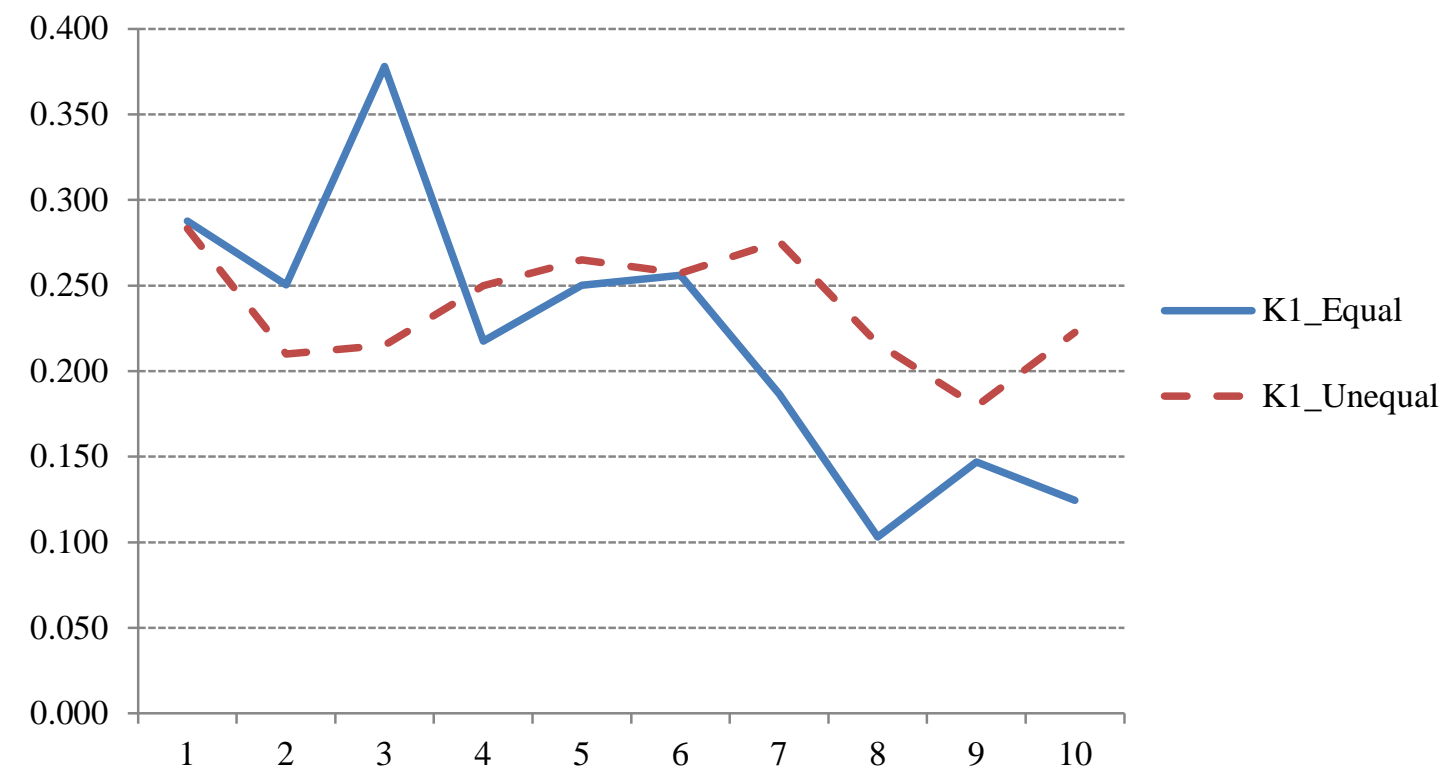

Another perspective that is worth stressing is that in the treatment with no ex ante inequality, a positive contribution of the active players generates a positive ex post inequality unfavorable to the patron. In fact, the average payoff of the patron turns out to be about $20 \%$ lower than that of the recipients. Such a result cannot be rationalized under the usual assumptions of the IA model, as it would require a negative $\alpha$. Other determinants must therefore be used to rationalize positive contributions, whose level constitutes further indirect evidence that IA does not play a significant role.

Given a selfish decision to contribute zero, it has often been suggested in the literature that positive contributions may be driven by decision errors or by an imperfect understanding of the game or of the incentive structure. To test the effect of confusion, we gathered selfreported information about the participants' comprehension of the game. We exploit this information by means of a dummy variable for the players that evaluated their comprehension 
of the rules as "null" or "poor."12 Indeed, we find that a self-reported bad understanding of the game positively correlates with the level of the contributions and tends to be significant in the first round of the game. However, the effect of confusion does not substantially affect the results across experimental conditions. In fact, the share of confused players in both treatments is very low ( 3 subjects at most). In addition, a Mann-Whitney test for the equality of populations confirms that the amount of confusion does not significantly differ across treatments $(\mathrm{p}=0.235)$. Finally, the results above are robust to the exclusion of the subjects who report a poor comprehension of the game. ${ }^{13}$

\section{Conclusions}

There is no consensus in the literature about the role that IA plays in explaining commonly observed departures from selfish behavior. IA models are difficult to falsify. In fact, by relying upon the heterogeneity of preferences at the individual level, IA models can rationalize a wide range of different outcomes. As a result, it is easy to find that results are consistent with preferences characterized by IA, and therefore this does not constitute a powerful test. On the other hand, any attempt to fit a single functional form to the infinite variety of preferences present in the population is bound to lead to some questionable results. Therefore, forcing a model to deliver point predictions would constitute an excessively demanding requirement.

In this paper, we propose a simple and direct test of the IA hypothesis based on aggregate results. We do so manipulating the degree of inequality in the Patron Game, an environment without strategic interaction and where IA does not compete with efficiency concerns. Exploiting a pure between subject design the exogenous change in ex ante inequality delivers a clean test of the IA models because it makes them falsifiable at the aggregate level, i.e., without relying upon any point prediction.

Our results show that the presence of an unequal endowment does not significantly alter the average contributions in the Patron Game, thereby providing evidence against the IA hypothesis. In addition to displaying an identical behavior on average, the treatments with and without inequality do not display any relevant difference in terms of either the distribution of individual contributions or their time pattern.

\footnotetext{
${ }^{12}$ We also have a variable capturing whether players agree with the statement "I have contributed randomly," but this variable does not significantly correlate with the observed contributions Results are not reported but are available upon request.

${ }^{13}$ Also other individual characteristics such as age, gender, political orientation or participation do not display a significant correlation with individual choices.
} 


\section{Acknowledgements}

We are grateful to the experimental laboratory of the University of Parma for logistic support. We also thank participants at the "Institutions in Context: Inequality" (School of Social Sciences and Humanities, University of Tampere) for their comments. IRB approval was not required by the hosting institution.

\section{References}

Abeler, J., Altmann, S., Kube, S., \& Wibral, M. (2010). Gift Exchange and Workers' Fairness Concerns: When Equality Is Unfair, Journal of the European Economic Association, 8, pp. 1299-1324.

Akerlof, G., A., \& Yellen, J., L. (1990). The fair wage-effort hypothesis and unenmployment. Quaterly Journal of Economics, 105, (2), pp. 255-283.

Anderson, L., R., Mellor, J., \& Milyo, J. (2003). Inequality, group cohesion, and public good provision: an experimental analysis. Working Paper

Andreoni, J. (1988). Why free ride? Strategies and Learning in Public Good Experiments. Journal of Public Economics, 37, pp. 291-304.

Andreoni, J. (1995a). Warm glow versus Cold-prickle: the effect of positive and negative framing on Cooperation in Experiments. Quaterly Journal of Economics, 109, pp. 1-21.

Andreoni, J. (1995b). Cooperation in public goods experiments: kindness or confusion? American Economic Review, 85, (4), pp. 891-904.

Andreoni, J., \& Miller, J. (2002). Giving according to GARP: an experimental test of the consistency of preferences for altruism. Econometrica, 70, pp.737-53.

Berg, J., Dickhaut J., \& McCabe, K. (1995). Trust, reciprocity, and social history. Games and Economic Behavior, 10, pp. 122-142.

Bewley, T. (2005). Fairness, reciprocity and wage rigidity. In: Gintis, H., Bowles, S., Boyd, R., \& Fehr, E., (Eds.), Moral Sentiments and Material Interests. The Foundations of Cooperation in Economic Life. Cambridge: The MIT Press, pp. 303-338.

Blanco, M., Engelmann, D. and Normann, T.H., (2011). A Within-subject analysis of otherregarding preferences. Games and Economic Behavior, 72 (2), pp. 321-338.

Bolton, G., E., \& Ockenfels, A. (2000). ERC: A Theory of Equity, Reciprocity, and Competition. American Economic Review, 90, (1), pp. 166-93.

Bolton, G., E., \& Ockenfels, A. (2006). Inequality aversion, efficiency, and maximin preferences in simple distribution experiments: Comment. American Economic Review, 96, pp. 1906-1911.

Buckley, E., \& Croson, R. (2006). Income and wealth heterogeneity in the voluntary provision of linear public goods. Journal of Public Economics, 90, pp. 935-955.

Burlando, R., \& Hey, J. (1997). Do Anglo Saxons free ride More? Journal of Public Economics, 64, (1), pp. 41-60. 
Cameron, L. (1995). Raising the stakes in the ultimatum game: experimental evidence from Indonesia. Economic Inquiry, 37, pp. 47-59.

Cardenas, J. (2002a). Real wealth and experimental cooperation: experiments in the field lab. Journal of Development Economics, 70, (2), pp. 263- 289.

Cardenas, J. (2002b). Wealth inequality and overexploitation of the commons: field experiments in colombia. Working Paper Series. Santa Fe Institute, Santa Fe, New Mexico.

Chan, K., S., Mestelman, S., Moir, R., \& Muller, R., A. (1996). The voluntary provision of public goods under varying income distributions. Canadian Journal of Economics, 96, pp. 54-69.

Charness, G. and Rabin, M., (2002). Understanding social preferences with simple tests. Quaterly Journal of Economics, 117 (3), pp. 817 - 869.

Engelmann, D. \& Strobel, M. (2004). Inequality Aversion, Efficiency, and Maximin Preferences in Simple Distribution Experiments. American Economic Review, 94, (4), pp. 857-869.

Fehr, E., Gaechter, S., \& Kirchsteiger, G. (1997). Reciprocity as a contract enforcement device: experimental evidence. Econometrica, 65, pp. 833-860.

Fehr, E., Kirchsteiger, G., \& Riedl, A. (1993). Does fairness prevent market clearing? An experimental investigation. Quarterly Journal of Economics, 108, pp. 437-460.

Fehr, E., \& Schmidt, K., M. (1999). A Theory of Fairness, Competition, and Cooperation. Quarterly Journal of Economics, 114, (3), pp. 817-868.

Fehr, E., Naef, M., \& Schmidt, K., M. (2006). Inequality Aversion, Efficiency, and Maximin Preferences in Simple Distribution Experiments: Comment. American Economic Review, 96 (5), pp. 1912-1917 .

Filippin, A. \& Raimondi, M. (2015), The Patron Game: Individual Determinants of the Contribution to the Public Good, mimeo.

Fischbacher, U. (2007). Zurich Toolbox for Readymade Economic Experiments. Experimental Economics, vol. 10(2), pp. 171-8.

Fisman, R., Kariv, S. and Markovits, D., (2007). Individual preferences for giving. American Economic Review, 97, pp.1858-1877.

Forsythe, R., Horowitz, J. Savin, N. E. and Sefton, M. (1994). Fairness in Simple Bargaining Experiments. Games and Economic Behavior, 6(3), pp. 347-69.

Goerg, S., J., Kube, S., \& Zultan, R. (2010). Treating Equals Unequally: Incentives in Teams, Workers' Motivation, and Production Technology. Journal of Labor Economics, 28, pp. 747-772.

Güth, W., Schmittberger, R., \& Schwarz, B. (1982). An experimental analysis of ultimatum game bargaining. Journal of Economic Behavior and Organization, 3, pp. 367-88.

Guth, W., Marchand, N., \& Rulliere, J. L. (1997). On the Reliability of Reciprocal Fairness; An Experimental Study. Discussion Paper, Humboldt University Berlin.

Iriberri, N. \&. Rey-Biel, P. (2011). The role of role uncertainty in modified dictator games. Experimental Economics, 14, (2), pp. 160-180. 
Isaac, R. M., \& Walker, J., M. (1988). Group Size Effects in Public Goods Provision: The Voluntary Contributions Mechanism. The Quarterly Journal of Economics, 103, (1), pp. 179-199.

Kahneman, D., Knetsch, J.L., \& Thaler, R. (1986b). Fairness as a constraint on profit seeking: entitlements in the market. American Economic Review, 76, pp. 728-741.

Keser, C. \& van Winden, F. (2000). Conditional Cooperation and Voluntary Contributions to Public Goods. Scandinavian Journal of Economics, 102, pp. 23-39.

Korenok O., Millner, E., L., \& Razzolini, L. (2012). Are Dictators Averse to Inequality? Journal of Economic Behavior and Organization, 82 (2-3), pp.543-547.

Ledyard, J. O. (1995). Public goods: a survey of experimental research. In: Hagel, J. H., Roth, A. E., (Eds.), Handbook of Experimental Economics, pp. 111-194.

Ockenfels, A., \& Weimann, J. (1996). Types and Patterns: An Experimental East-West Comparison of Cooperation and Solidarity. Journal of Public Economics, 71, (2), pp. 275- 87.

Roth, A., E., Prasnikar, V., Okuno-Fujiwara, M., \& Zamir, S. (1991). Bargaining and market behavior in Jerusalem, Ljubljana, Pittsburgh and Tokyo: an experimental study. American Economic Review, 81, pp. 1068-1095.

Shaked, A. (2006). On the explanatory value of inequity aversion theory. Working Paper, Bonn University.

Slonim, R., \& Roth, A., E. (1997). Financial incentives and learning in Ultimatum and Market Games: an experiment in the Slovak Republic. Econometrica, 66, (3), pp. 569-596.

Varughese, G., \& Ostrom, E. (2001). The Contested Role of Heterogeneity in Collective Action: Some Evidence from Community Forestry in Nepal. World Development, 29, (5), pp. 747-765.

Winter, E. (2004). Incentives and Discrimination. American Economic Review, 94, pp.764773.

Yamagishi, T., Horita, Y., Takagishi, H., Shinada, M., Tanida, S., and Cook, K. (2009). Private rejection of unfair offers and emotional commitment. Proceedings of the National 


\section{Appendix A}

\section{INSTRUCTIONS (translated from Italian)}

Welcome, and thank you for participating in this experiment; its purpose is to analyze economic decision making. You will receive 2.5 Euros for showing up. Moreover, if you carefully follow these simple instructions, you will understand how to earn some money according to the decisions you and your colleagues will undertake during the game. The Department of Economics of the University of Milano has provided the funds for this study.

Remember that the decisions you make are strictly anonymous. Data collected during the experiment will be analyzed, elaborated and published only in aggregate form and for the unique purpose of scientific research. In no way can the experimenters or any other person retrieve personal information from the data collected because we use a unique personal ID, which is the number tag that you have randomly drawn at the entrance and which identifies your workstation.

The number tag is essential to collect your earnings. Be careful not to lose it because it is the only way in which we can identify your earnings at the end of the experiment.

\section{THE GAME}

This is a simple 10-round game based on the following rules.

At the beginning of the experiment, each of the participants will be randomly matched with three other subjects to form a 4-person group. The group will be composed of the same 4 subjects during the entire experiment.

In each group, a randomly selected player will be "active", and the other three players will be "passive". Each of the passive players will be endowed in each round with 100 eurocents [50 eurocents in K1_Unequal]. The active player will be endowed with 100 eurocents [150 eurocents in K1_Unequal]. If you are selected to be "active", you can choose how to divide your endowment between these opportunities:

A - Individual Account: you can keep (part of) your endowment for yourself. The money that you keep in each round enters directly into your individual earnings.

B - Investment Fund: you can allocate (part of) your endowment to a public fund. This fund collects the money allocated for this purpose within each group. The fund gains a positive return because the amount collected yields an interest rate of 50 percent (i.e., the sum of contributions is multiplied by 1.5). This value of the investment fund is then equally divided between the 4 participants.

You must decide in each round how to allocate between the Individual Account and the Investment Fund.

You are free to allocate all of your endowment into the Individual Account or into the Investment Fund, as well as to split it in any way that you prefer. 
The game will proceed as soon as all of the participants have made their choices and pressed the "OK" button (you have 30 seconds to decide). At the end of each round the contribution to the fund as well as your individual earnings will be displayed.

Your final earnings will be the sum of the Individual Account and the proceeds from the Investment Fund in each round plus the 2.5 euro show-up fee. At the end of the experiment, you will see your final earnings on the monitor.

A good comprehension of the game is crucial for your earnings as well as for the strength of the data collected. Hence, if you have any questions, please raise your hand and ask, even during the quizzes that are going to start.

It is forbidden to communicate with other players. Thank you. 
